\title{
REVISÃO DOS CONHECIMENTOS SOBRE O SIGNIFICADO DAS LINHAS DE SEIXOS
}

\author{
Silvio Takashi HIRUMA
}

\begin{abstract}
RESUMO
O termo linha de seixos corresponde a um horizonte de fragmentos grossos, resistentes à alteração química, freqüentemente encontrado no interior de coberturas pedológicas das zonas intertropicais. Apesar de mencionadas na literatura desde o século XIX, a origem alóctone ou autóctone dessas feições é um tema que ainda desperta polêmica no meio científico, alvo de inúmeros estudos desenvolvidos por pedólogos, biólogos, geólogos e geomorfólogos. A presente contribuição tem por finalidade discutir as hipóteses sobre a origem das linhas de seixos e os métodos de análise.
\end{abstract}

Palavras-chave: linhas de seixos, paleopavimento, intemperismo, ação biológica, colúvio, Quaternário

\section{ABSTRACT}

The term stone-line corresponds to a horizon of coarse rock fragments, resistant to weathering, often found within the pedological cover in intertropical zones. Though mentioned in the literature since the nineteenth century, the origin of these features, whether autochthonous or allocthonous, is a subject that still arouses controversy in the scientific community, and is the target of numerous studies by pedologists, biologists and geomorphologists. This contribution discusses hypotheses on the origin of stonelines and methods for their analysis.

Keywords: stone-lines, paleopavement, weathering, biological action, colluvium, Quaternary

\section{INTRODUÇÃO}

O termo linha de seixos ou linha de pedras (stone-line) refere-se a um horizonte de fragmentos angulosos a subangulosos, às vezes arredondados, de quartzo de veio, quartzitos, couraças lateríticas, minerais pesados, ou de outros materiais resistentes à alteração química, presente no interior da cobertura pedológica em vastas áreas das zonas intertropicais. Em geral, as linhas de seixos dispõe-se mais ou menos paralelamente à superfície topográfica, sendo limitada acima por um horizonte relativamente homogêneo de textura areno-síltico-argilosa, e, abaixo, pela rocha alterada. Trata-se de uma definição descritiva, sem conotações genéticas. Conforme AB'SÁBER (1996), a distribuição dessas feições no Brasil é ampla, abrangendo uma grande diversidade de paisagens, desde as pradarias e baixos platôs do Rio Grande do Sul até as regiões florestadas de Rondônia, Amapá e Roraima, das colinas de Cuiabá até setores do Planalto da Borborema.

A origem das linhas de seixos e de seu material de recobrimento ainda é um tema muito debatido; a questão principal diz respeito ao seu caráter autóctone ou alóctone. A diversidade de teorias está bem expressa nas revisões de AB'SÁBER (1962), VOGT (1966), SEGALEN (1969), e, mais recentemente, THOMAS (1994). Também merecem destaque as importantes observações feitas sobre o tema durante o XVIII Congresso Internacional de Geografia (UGI), no Rio de Janeiro, em 1956, publicadas em volumes da Zeitschrift für Geomorphologie, e na jornada de estudos de 24 de março de 1987, em Bruxelas, registrada no volume 11 (1-4) da Geo-Eco-Trop. A presente contribuição tem por finalidade apresentar as hipóteses de origem das linhas de seixos e discutir os processos envolvidos e os métodos de análise. 


\section{PROCESSOS DE GERAÇÃO DAS LINHAS DE SEIXOS E DOS MATERIAIS DE RECOBRIMENTO}

A concentração de fragmentos grossos que compõem uma linha de seixos e seu recobrimento podem ser resultado de um único ou diversos processos, atuantes sob condições ambientais específicas. A linha de seixos pode-se formar num único processo (desenvolvimento in situ), sob condições climáticas constantes, ou a partir de processos sucessivos (desenvolvimento alóctone), quando ocorre mudança das mesmas; neste último caso, a presença das linhas de seixos possui importantes implicações paleoclimáticas e paleoecológicas (VOGT 1966).

Em sua revisão no livro Geomorphology in the tropics, THOMAS (1994) sintetizou os processos que levariam à acumulação de cascalhos e à formação do material de cobertura, sob diferentes tipos de clima e de vegetação (Tabela 8.5, pg. 275). As diversas combinações de processos podem ou não implicar necessariamente em mudanças ambientais. Conforme o autor é provável que a maior parte das linhas de seixos evolua a partir de vários estágios: (1) acumulação residual resultante da dissolução e remoção de materiais finos e intemperizáveis sob condições úmidas, (2) redistribuição e concentração de cascalhos por escoamento superficial e coluvionamento associado e (3) modificação e recobrimento por bioturbação, rastejo, cavidades produzidas por árvores (tree throw) e, possivelmente, atividade antrópica.

Não serão enfocadas nesta síntese as observações pioneiras realizadas nos séculos XIX e início do XX sobre o tema, uma vez que já foram discutidas em detalhe nas revisões de AB'SÁBER (1962) e VOGT (1966). Cabe ressaltar que parte dessas observações relacionava a origem das linhas de seixos a teorias catastrofistas ou a eventos glaciais, que não foram mais defendidas com o avanço dos estudos nas décadas seguintes.

Face à dificuldade em se desvincular, muitas vezes, os processos de formação da linha de seixos do seu recobrimento, procurou-se nessa síntese agrupar as diferentes hipóteses segundo a natureza do processo dominante.

\subsection{Paleopavimentação detrítica}

Segundo esta teoria, a linha de seixos seria formada a partir do enriquecimento relativo de fragmentos grossos pela perda das frações mais finas em superfície, seguido por uma deposição de material fino por processos variados (aporte eólico, coluvionamento ou ação de térmitas). Condições drásticas de aridez ou semi-aridez, ou fases morfogenéticas de instabilidade, são comumente evocadas para explicar sua origem. Esta hipótese aloctonista foi defendida por vários autores: DE HEINZELIN (1952, 1955), RUHE (1956, 1959 in THOMAS 1994), PARIZEK \& WOODRUFF (1957), DE PLOEY (1964), BOURGEAT \& PETIT (1966), SEGALEN (1969), RIQUIER (1969), FAIRBRIDGE \& FINKL (1984), EMBRECHTS \& DE DAPPER (1987, 1990), OZER (1987), DE DAPPER (1987), LANFRANCHI \& SCHWARTZ (1991), entre outros.

No Brasil, a hipótese de paleopavimento detrítico foi defendida por AB'SÁBER em sua revisão de 1962, e em diversos trabalhos posteriores (AB'SÁBER, 1969 a, b, c, 1971, 1977, 1979, 1996, 2003), a partir de observações realizadas em diversos compartimentos geomorfológicos.

Conforme AB'SÁBER (1962), o paleopavimento seria formado por fragmentos e seixos retrabalhados, depositados sob a forma de chão pedregoso em período seco esporádico - provavelmente do tipo semi-árido moderado -, com vegetação rala e esparsa que favoreceria o escoamento superficial. Nessa época, a paisagem seria semelhante à observada em setores do Nordeste semi-árido, onde hoje atuam processos de pavimentação detrítica. A topografia anterior à formação do paleopavimento possuiria um grau de energia próximo do atual, porém, durante o processo, encontrar-se-ia rebaixada em seus micro-relevos por ravinamentos rasos e laminares. A cobertura detrítica fina acima das linhas de seixos estaria associada à umidificação do clima - posterior à fase de pavimentação detrítica - e se originaria da decomposição das rochas situadas acima dos leitos detríticos em vertentes escarpadas ou "calombos" e "cabeços". Processos de coluvionamento seriam responsáveis pelo espalhamento dos detritos. Suas idéias coincidem, muitas vezes, com as de TRICART (1958), RAYNAL (1957) e LEHMANN (1957), que já apontavam em direção à variação das condições morfoclimáticas.

DE PLOEY (1964) defendeu a mesma hipótese para as ocorrências de linhas de seixos no Baixo Congo e associa a formação do paleopavimento às condições de aridez durante o último máximo glacial.

Interpretações semelhantes foram feitas no Brasil pelo Professor João José Bigarella e colaboradores. Conforme BIGARELLA \& MOUSINHO 
(1965), o recuo de áreas florestadas sob períodos secos suficientemente longos levaria à exposição do solo, com conseqüente remoção dos materiais finos e concentração dos fragmentos mais pesados, originando o paleopavimento. No entanto, como salientado por BIGARELLA \& ANDRADE (1965), tais condições não teriam sido tão severas ou extensas quanto aquelas que deram origem aos pedimentos e pediplanos. MOUSINHO \& BIGARELLA (1965) consideram que a maioria dos seixos do paleopavimento originar-se-ia do retrabalhamento de pedimentos e terraços.

Quanto à idade das linhas de seixos, TRICART (1958), assim como AB'SÁBER (1962, 1971, 1973), relacionaram os paleopavimentos à última fase seca esporádica que afetou o Brasil Atlântico no fim do Flandriano. No entanto, no fim da década de 70, AB'SÁBER $(1979,1980)$ passou a atribuir a "época principal" de formação dos paleopavimentos ao último período glacial do Pleistoceno terminal (Wurm/Wisconsin Superior), em concordância com BIGARELLA \& ANDRADE (1965). Conforme $\mathrm{Ab}$ 'Sáber, somente este período seco teria força suficiente para reduzir a temperatura, estender as correntes frias pelo lado oriental da América do Sul e tornar o ambiente seco em grandes setores dos planaltos compartimentados do Brasil.

A recorrência pretérita dos fenômenos climáticos seria evidenciada pela existência de vários níveis de paleopavimentos detríticos superpostos ou em discordância angular, seguidos por materiais coluviais de características diversas (BIGARELLA \& MOUSINHO 1965). PENTEADO (1969), estudando a área de Rio Claro e vizinhanças, reconheceu duas linhas de seixos com artefatos arqueológicos, intercaladas com colúvios e paleossolos, situadas entre o pedimento detrítico inferior e a superfície atual dos solos. Ab'Sáber, ao tomar conhecimento da descoberta de duas linhas de seixos no Planalto de Campos do Jordão (MODENESI 1988) uma, de ocorrência generalizada em todo o País, provavelmente relacionada ao principal período de semi-aridez do Pleistoceno Terminal, outra, descontínua, de fase intra-holocênica de clima mais seco observa que esta última também aparece em alguns pontos do sul do Brasil, como Rio Grande do Sul e Santa Catarina, e região sublitorânea de Cabo Frio (AB'SABER in MODENESI 1988).

Apesar de considerar a maior parte das ocorrências de linhas de seixos no Brasil registros irrefutáveis de antigos chãos pedregosos, AB'SÁBER (1979) alerta para o excesso de generalizações sobre o seu significado paleoclimático. Como salienta o autor, "se é que as linhas de pedras documentam sempre climas mais secos do que os atualmente vigentes, elas certamente estiveram associadas a diferentes ambientes térmicos, não sendo capazes de sugerir diretamente as condições ecológicas específicas das áreas de sua ocorrência, nem, tão pouco, o patrimônio vegetal exato que teria existido nos setores onde elas ocorrem". Um fato importante ressaltado por AB'SÁBER, ao retomar essa questão em 1996, é a necessidade de se considerar nas análises não somente a zonação latitudinal das paleopaisagens, como também, a altitudinal. Por exemplo, nas colinas do Médio Vale do Paraíba as linhas de seixos documentariam climas secos intermontanos do passado recente, no planalto do Itatiaia, ambientes periglaciais, e em Campos do Jordão e Monte Verde, paisagens subestépicas.

A idéia de paleopavimentação detrítica associada a fases de climas áridos e semi-áridos foi adotada em uma infinidade de trabalhos posteriores no Brasil durante as décadas seguintes, que consideram a linha de seixos um importante registro paleoecológico e marco estratigráfico.

No entanto, segundo outras teorias, a concentração de elementos grossos em superfície não implicaria necessariamente em condições drásticas de aridez ou semi-aridez (BOURGEAT \& PETIT 1966, RIQUIER 1969, SEGALEN 1969, EMBRECHTS \& DE DAPPER 1987, 1990). Processos de coluvionamento cíclicos associados a recuo de vertentes e atuantes em clima tropical também explicariam a formação do paleopavimento erosivo e seu recobrimento.

BOURGEAT \& PETIT (1966), estudando as linhas de seixos das terras altas de Madagascar, consideram pouco provável a existência de uma fase climática de extrema aridez em uma época relativamente recente. Os autores consideram que as linhas de seixos nas vertentes tenham se formado no decorrer de duas fases climáticas distintas (climas tropicais com duração e intensidade da estação seca contrastantes). Nas fases de estação seca acentuada (semelhante à atual) haveria a formação de lavakas (tipo de boçorocamento) e erosão intensa, favorecendo o espalhamento de material grosso; já as fases mais úmidas favoreceriam a deposição dos elementos finos por coluvionamento.

Conforme RIQUIER (1969), a gênese das linhas de seixos em regiões tropicais e equatoriais (Madagascar e Congo-Brazzaville) seria um processo cíclico no decorrer do tempo, mas não constante, com interrupções das fases de erosão e coluvionamento. Períodos secos de clima desértico não 
seriam necessários para a atuação de tais processos; estações secas longas (4 a 5 meses) e chuvas de 800 a $2.000 \mathrm{~mm}$ já seriam condições suficientes.

SEGALEN (1969), a partir de observações realizadas na África tropical, desenvolveu o modelo de inversão de materiais (retournement), aplicando-o em áreas de antigas superfícies aplainadas capeadas por couraças terciárias e delimitadas por escarpas. Segundo esse modelo, o recuo erosivo das vertentes promoveria uma inversão de materiais na base da vertente: fragmentos grossos da couraça laterítica, desmantelada e fragmentada, recobertos por material fino retido pela vegetação arbórea, produto da erosão do material subjacente. Em áreas pré-desérticas, onde a cobertura vegetal é insuficiente para prender os finos, surgiriam os campos de cascalho. Já em regiões equatoriais (Congo e Gabão), onde a cobertura vegetal é contínua e a erosão menos intensa, a presença de linhas de seixos evidenciaria uma evolução pretérita sob clima tropical; nas condições atuais, a erosão química, conjugada ao processo de rastejo, provocariam sucessivas deformações no perfil original.

Mais recentemente, EMBRECHTS \& DE DAPPER $(1987,1990)$ associaram a formação das linhas de seixos a processos cíclicos de pedimentação atuantes em climas tropicais com estação seca curta.

\subsection{Ação biológica}

No domínio tropical a ação biológica desempenha um importante papel no transporte de materiais a grandes profundidades, nas mudanças da estrutura física do solo e na formação de novos solos (GRASSÉ \& NOIROT 1959, BOYER 1959).

As evidências a favor da ação biológica no remonte de materiais acima das linhas de seixos são baseadas (1) nas similaridades da granulometria, morfoscopia e mineralogia entre as formações acima e abaixo das linhas de seixos, (2) na extensão e volume das partículas trazidas à superfície pelos animais do subsolo e (3) na bioturbação detectada por técnicas micromorfológicas (SOYER 1987). Na África e no Brasil, autores como CAILLEUX (1957), CAILLEUX \& TRICART (1957), DE PLOEY (1964), ALONI (1975), ALONI KOMANDA (1978a, b), SOYER (1987), MIKLOS (1992, 1993) e NICOLA (1993), entre outros, investigaram o papel da ação biológica no desenvolvimento das linhas de seixos.

A hipótese de ação biológica foi defendida por CAILLEUX (1957), ao observar a similarida- de das dimensões dos grãos de quartzo das partes aéreas de vários cupinzeiros com os grãos maiores dos solos amarelos acima da linha de cascalhos. $\mathrm{O}$ autor excluiu a origem eólica para esses materiais pela análise morfoscópica dos grãos e grau de seleção e descartou, ainda, os processos de deslizamento de solos, considerando que nestes casos os seixos estariam misturados ao material fino. Técnicas semelhantes foram empregadas por DE PLOEY (1964) na região do Baixo Congo. Para algumas coberturas argilo-arenosas, o autor atribuiu a ação do escoamento superficial e coluvionamento após o fim do período subárido; no entanto, em pelo menos um dos casos analisados, quando a cobertura encontra-se sob topos aplainados, considerou o aporte pelas térmitas a hipótese mais aceitável.

A concentração in situ dos fragmentos grossos no interior do perfil de solo foi defendida por LAPORTE (1962 apud BOURGEAT \& PETIT 1966), ao estudar as linhas de seixos da África Central (Congo - Brazzaville). Conforme o autor, não haveria uma descontinuidade estratigráfica entre a linha de seixos e sua cobertura. A separação dos elementos finos e grossos seria explicada por uma homogenização biológica na cobertura, que promoveria a descida dos elementos grossos por gravidade, favorecida pelas propriedades físicas do material fino fluidificado, ou por ciclos de umedecimento e ressecamento. CAHEN \& MOEYERSONS (1977) desenvolveram experimentos envolvendo ciclos de umedecimento e ressecamento em sedimentos para observar a dispersão vertical de artefatos em coberturas arenosas no Kalahari. Os autores sugerem a influência da ação biológica no remonte de material para a superfície, seguido pelo colapso das estruturas biogênicas, levando à consolidação da coluna de solo e à concentração dos elementos grossos.

ALONI (1975) estudou a evolução morfológica dos cupinzeiros gigantes do Alto Shaba (África) e suas relações com diferentes tipos de solos, considerando os parâmetros de estrutura, granulometria e limites de Atterberg. Segundo o autor, nessas regiões, os cupinzeiros podem alcançar $10 \mathrm{~m}$ de altura e $30 \mathrm{~m}$ de diâmetro ou, mais usualmente, $5 \mathrm{~m}$ de altura e $10-12 \mathrm{~m}$ de diâmetro; após seu abandono, sofrem rápida erosão, fornecendo detritos finos para a superfície do solo. ALONI KOMANDA (1978b), no entanto, ressalta a falta de dados quantitativos sobre a influência de térmitas na gênese das formações superficiais e propõe técnicas visando simplificar as pesquisas e uniformizar os procedimentos, de 
modo que os resultados possam ser comparados. Assim, o autor prioriza três elementos essenciais para a análise: (1) quantificação do material erodido dos cupinzeiros, (2) redistribuição e modificações do espectro granulométrico sofrido pelo material erodido e (3) diferença de composição textural entre os cupinzeiros e os solos limítrofes.

Partindo-se da análise estrutural da cobertura pedológica, MIKLOS $(1992,1993)$ avaliou a importância da ação biológica na pedogênese em um setor do reverso da escarpa arenítico-basáltico em Botucatu (Planalto Ocidental paulista). Estudos micromorfológicos das diferentes organizações pedológicas e litológicas permitiram caracterizar de modo qualitativo e quantitativo a ação de integrantes da fauna (térmitas, formigas e minhocas) na cobertura pedológica. As seguintes modificações de natureza física e química foram atribuídas à ação biológica: remonte vertical de material do solo e recobrimento dos horizontes superficiais (enterramento de linhas de seixos e horizonte sômbrico), modificações das estruturas e das propriedades dos solos (formação de agregados granulares/grumosos e construção de canais) e heterogenização das cores do solo. Seguindo metodologia semelhante, NICOLA (1993) discutiu as seguintes hipóteses para a gênese das linhas de seixos presentes em uma cobertura pedológica sobre basaltos do Grupo São Bento (Ilha Solteira, SP): translocação mecânica devido à expansão de argilas, influência de térmitas e coluvionamento.

Conforme THOMAS (1994), camadas de solo superficial homogenizado pela ação biológica de 3 a $5 \mathrm{~m}$ de espessura teriam idades mínimas de 6.000 - 10.000 anos, sem considerar os processos de pedoturbação e as taxas de erosão superficial.

AB'SÁBER, em sua revisão de 1962, apresentou argumentos contrários à ação das térmitas na gênese das linhas de seixos. Na região da Serra do Japi, na Depressão Periférica paulista e nos planaltos basálticos ao sul de Lajes, o arranjo espacial nas vertentes e as relações de contato com os materiais sotopostos e a rocha subjacente evidenciam o caráter coluvial da cobertura das linhas de seixos. Conforme o autor, em quase todo o Brasil, "as construções efetuadas por cupins e formigas têm um aspecto ganglionar ou labiríntico, importante para uma cimentação subaérea e subterrânea descontínua dos edifícios de formigueiros e cupinzeiros, mas incapaz de forçar acréscimos regulares per acenzo, em toda uma superfície horizontal". Em solos imaturos e secos de clima semi-árido, ou herdados de climas localmente secos, uma ação universal dos cupins ou das formigas seria pouco provável, mesmo durante a mudança climática. $\mathrm{O}$ autor salienta, ainda, a inexistência, nos casos analisados até aquele momento, de evidências de retrabalhamento no embasamento alterado que serve de base às linhas de seixos, bem como sua notável espessura, continuidade espacial, densidade na inter-acomodação entre os seixos, que inviabilizariam o transporte ascensional de grandes volumes, capazes de recobrir toda uma vertente. Apesar das considerações acima, o autor ressalta a importância de melhor entender a dinâmica dos processos superficiais desencadeados por tais organismos no interior e na superfície dos solos dos países tropicais úmidos.

Embora a maior parte dos trabalhos tenha enfocado principalmente o papel das térmitas, outros organismos também podem contribuir para a geração das linhas de seixos. A ação de mamíferos roedores no remonte de material e na acumulação de elementos grossos, por exemplo, foi alvo dos estudos de JOHNSON (1989) na Califórnia e de MBENZA et al. (1987) no Shaba.

\subsection{Processos geoquímicos}

As linhas de seixos, segundo esta hipótese, constituiriam os produtos residuais do intemperismo a partir de processos de diferenciação in situ, no interior do perfil de alteração, que levariam à concentração dos elementos grossos (COLLINET 1969; ALEVA 1983, 1991; THOMAS \& THORP 1985; MCFARLANE \& POLLARD 1987; LECOMTE 1988; LUCAS et al. 1990; entre outros). Esse processo pôde ser melhor interpretado com o avanço das teorias sobre etchplanação (WAYLAND 1933; WILLIS 1936; BÜDEL 1957; THOMAS \& THORP 1985; THOMAS 1989a, b) e das superfícies de aplainamento triplas (ALEVA 1983). De modo geral, entende-se que os processos de desestruturação e colapso causados pela saída de material fino e em solução, com o avanço da frente de intemperismo, são acompanhados por uma renovação do solo, promovida pela ação biológica.

QUEIROZ NETO (2001), em sua síntese sobre a evolução das pesquisas e dos conhecimentos a respeito das formações superficiais no Brasil, destacou o importante papel dos processos geoquímicos e pedogenéticos na elaboração do relevo, alertando para o perigo de se interpretar 
indiscriminadamente couraças, linhas de seixos e/ ou concreções ferruginosas, entre outras feições, e características observadas no perfil de alteração como indícios de descontinuidades litológicas ou de superposição de materiais.

Na região do Gabão, caracterizada pela profunda alteração das rochas e evolução ferralítica, COLLINET (1969) observou modificações no perfil das linhas de seixos geradas pelo esquema de inversão de materiais em clima tropical (SEGALEN 1969), em função da nova evolução pedogenética equatorial. Para alguns perfis, onde a linha de seixos é unicamente constituída por elementos residuais pouco alterados da rocha-mãe subjacente, defende um desenvolvimento inteiramente autóctone.

MCFARLANE \& POLLARD (1987) estudaram ocorrências de linhas de seixos em perfis de dambos nas regiões de Malawi e Zimbabwe, associadas a uma frente de dissolução na interface entre o saprólito e os materiais superficiais. Os autores observaram que, em alguns casos, essa interface é muito irregular, convoluta ou transicional, com clastos de saprólito acima da frente de dissolução, evidenciando o caráter residual dessas feições. A transformação do saprólito em colúvio arenoso envolveria a remoção de caolinita por processos de dissolução, com a possível influência de agentes microbiológicos.

A hipótese de translocação mecânica é defendida por LECOMTE (1988) ao estudar os perfis de alteração na região do Gabão (África). Análises químicas e mineralógicas comprovaram que as linhas de seixos resultariam da lixiviação química e do movimento diferencial entre a matriz e os fragmentos grossos no perfil de alteração.

LUCAS et al. (1990) verificaram o desenvolvimento in situ das linhas de seixos de nódulos ferruginosos presentes nas coberturas ferralíticas dos platôs da parte central da Amazônia, que seria promovido pelo aprofundamento geoquímico na rocha sã, com o avanço das frentes de transformação. Os autores observaram que as condições de formação e estabilidade dos nódulos não permanecem nas vertentes, onde ocorre o afinamento e desaparecimento das linhas de seixos por processos de dissolução.

Muitas vezes, como observado por COLLINET (1969), SEGALEN (1969), THOMAS \& THORP (1985) e WELLS et al. (1990), o rebaixamento da superfície topográfica pelo processo de etchplanação promoveria o retrabalhamento sucessivo das linhas de seixos, evidenciando seu caráter poligenético .

\section{NOVOS MÉTODOS E CONCEPÇÕES}

\subsection{Geomorfologia experimental}

Nas últimas décadas o avanço dos estudos de geomorfologia experimental permitiu uma melhor interpretação da dinâmica sedimentológica dos depósitos quaternários, inclusive das linhas de seixos. DE PLOEY \& POESEN (1989) analisaram o papel dos processos pluviais que levariam a formação e destruição dessas feições: erosão em lençol (sheetwash), impacto da gota de chuva (splash creep), micro-movimentos induzidos por fluxo turbulento (runoff creep), erosão em filetes (rill erosion) e coluvionamento.

DE PLOEY (1985) fez considerações sobre a transportabilidade dos seixos e os efeitos da cobertura de cascalho no escoamento superficial e na intensidade de erosão pluvial. Se por um lado, essa cobertura contribui para a impermeabilização do solo e conseqüente aumento do escoamento superficial, por outro, quando muito densa, promove uma proteção da superfície do solo contra a erosão pluvial. Citando dados experimentais obtidos por Poesen, o autor ressalta que a evacuação de detritos grossos pelo escoamento nas áreas entre filetes d'água (interrills) é muito difícil, ao contrário do que ocorre no interior dos filetes. Dessa forma, seixos temporariamente depositados em colúvios de vertente poderiam ser transportados, em seguida, pelos filetes. A alternância entre processos de transporte e erosão poderia explicar a gênese de linhas de seixos com vários níveis de cascalho.

Seguindo a mesma linha experimental, MOEYERSONS (1987) observou a importância dos processos de rastejo na formação das linhas de seixos e do material de recobrimento em Ruanda, a partir de medidas in situ de deformação do solo nas vertentes. Conforme o autor, a erosão mecânica, causada pela percolação de águas ao longo de descontinuidades existentes entre horizontes de solos texturalmente diferentes, poderia resultar na perda de material fino e concentração de fragmentos grossos. THOMAS (1994) considera, no entanto, que o rastejo não seria o processo dominante em vertentes de baixa declividade $\left(<5^{\circ}\right)$, onde as linhas de seixos também estão presentes.

Ao discutir o modelo de LAPORTE (1962), MOEYERSONS (1987) considerou que, sob condições de elevada pressão de água nos poros, fragmentos grossos poderiam descer por gravidade no interior do solo. O autor considera, no entanto, pouco provável a vigência de tais condições para explicar a presença de linhas de seixos em áreas de interflúvio das 
regiões tropicais. Uma questão a ser ainda explorada é se eventos sísmicos, comumente associados à geração de estruturas de liquefação, poderiam promover a separação de fragmentos finos e grossos no perfil de solo em escala regional. A hipótese de sismicidade é aventada por RODRIGUEZ (1994) para explicar a ocorrência de gradação inversa dos tamanhos dos fragmentos em linhas de seixos da região de Altamira (PA). Conforme o autor, vibrações sísmicas promoveriam a passagem rápida e descendente dos fragmentos mais finos por entre os vãos dos mais grossos (efeito "saleiro"). Evidências de neotectônica na região dariam suporte a essa idéia.

\subsection{Análises geoquímicas de multielementos}

Mais recentemente, foram desenvolvidas técnicas de análises geoquímicas de multielementos, que permitem obter com precisão as assinaturas geoquímicas do saprólito, linha de seixos e do material de cobertura. Tais técnicas foram empregadas no Gabão por LECOMTE (1988) para estudar os processos de dispersão geoquímica em perfis de intemperismo com linhas de seixos.

BROWN et al. (2004) efetuaram análises químicas de elementos terras-raras (La-Lu) e elementos índices (Th, Sc e Hf) para verificar as diferenças composicionais entre os materiais de cobertura das linhas de seixos e o saprólito em perfis de intemperismo em Uganda. Como ressaltado pelos autores, a similaridade das propriedades químicas e das associações mineralógicas dos elementos terras-raras, aliada a sua baixa solubilidade, permite que eles sejam comumente empregados na geologia sedimentar para distinguir os materiais de origem. Uma prática comum é a de quantificar a mobilidade dos elementos terras-raras em relação a elementos-índices de baixíssima mobilidade, como o Th, Sc e Hf. Uma vez que tais elementos encontram-se associados aos mesmos tipos de argila e óxidos de ferro em paisagens muito intemperizadas, as razões obtidas entre esses elementos não seriam afetadas por processos mecânicos como erosão, deposição e bioturbação, podendo indicar portanto, um índice de alteração dos solos.

\subsection{Análise de isótopos cosmogênicos}

Essa análise baseia-se na concentração de nuclídeos cosmogênicos produzidos in situ em solos e rochas nas porções mais superficiais da crosta terrestre. Esta técnica fornece um registro quantitativo da exposição próximo à superfície, que é muito interes- sante para estudos sobre a evolução de solos (vide revisão detalhada sobre o assunto em COCKBURN \& SUMMERFIELD 2004).

A partir da análise do isótopo cosmogênico ${ }^{3} \mathrm{He}$, WELLS et al. (1995) propuseram um modelo de formação dos pavimentos de pedra em desertos. A mesma técnica, utilizando porém o isótopo ${ }^{10} \mathrm{Be}$, foi aplicada para determinar os processos envolvidos na geração das linhas de seixos em perfis lateríticos na África (BRAUCHER et al. 1998a) e no Brasil (BRAUCHER et al. 1998b, 2004). A partir das concentrações de ${ }^{10} \mathrm{Be}$ obtidas ao longo das linhas de seixos, os autores conseguiram diferenciar processos alóctones e in situ, e, no último caso, quantificar as taxas de deslocamento lateral de seus componentes da área fonte (veios de quartzo). Na Bacia do Rio Jardim (Distrito Federal), BRAUCHER et al. (2004) observaram que o aumento sistemático das concentrações de ${ }^{10} \mathrm{Be}$ ao longo de uma linha de seixos, em função da distância da área fonte (veio de quartzo), estaria associada a um desenvolvimento autóctone. No caso de uma origem alóctone, a concentração de ${ }^{10} \mathrm{Be}$ ao longo de uma linha de seixos seria constante.

\section{IMPLICAÇÕES PRÁTICAS DO ESTUDO DAS LINHAS DE SEIXOS}

O estudo das linhas de seixos apresenta implicações práticas em diversas áreas, como levantamento geológico, prospecção mineral, engenharia civil, agricultura, arqueologia, entre outras (VOGT 1966), como exemplificadas a seguir.

As linhas de seixos podem fornecer importantes informações para a geologia (VOGT 1966). Em alguns casos, a presença de fragmentos de rochas exóticas nas linhas de seixos, que atualmente afloram a longas distâncias, poderia evidenciar que tais rochas ocupavam uma maior extensão no passado. Para se comprovar essa hipótese, no entanto, é necessário que haja uma compreensão da origem das linhas de seixos e da evolução geomorfológica da região.

Em linhas de seixos desenvolvidas in situ, seja pela ação de térmitas ou por processos de diferenciação, o material de cobertura pode fornecer informações importantes sobre as rochas do subsolo, especialmente em áreas sem afloramentos.

Muitas vezes as linhas de seixos podem concentrar minerais resistentes ao intemperismo e de valor econômico, como cassiterita, columbita, ouro, monazita, zircão, rutilo, ilmenita e diamante (THORP 1987), ou indicar anomalias geoquímicas de interesse para a prospecção mineral (LECOMTE 1988). Para ALEVA (1987), amostragens efetuadas em linhas de 
seixos podem ser um meio simples, barato e eficaz de verificar a presença de minerais de interesse econômico, que podem estar concentrados nos placers fluviais. Por outro lado, a ausência das linhas de seixos pode ser um indicativo da escassez de minérios, comumente associados a veios de quartzo. Em escala regional, VOGT (1966) destaca que o melhor conhecimento da linha de seixos mineralizada poderia resolver o problema de origem e migração dos diamantes.

LECOMTE (1988) reconheceu um padrão de dispersão de elementos associado a anomalias geoquímicas em perfis de linhas de seixos desenvolvidos in situ na região do Gabão, de especial interesse para a prospecção mineral.

Processos de reprecipitação química na superficie de fragmentos de quartzo ferruginizado das linhas de seixos podem concentrar o ouro, como relatado por PORTO \& HALE (1995), ao estudar os perfis lateríticos do depósito aurífero de Posse (Brasil Central).

A linha de seixos também é um rico reservatório de artefatos arqueológicos, o que motivou diversos autores a discutir o significado estratigráfico, cronológico e paleoclimático de tais ocorrências (cf. LANFRANCHI \& SCHWARTZ 1991, SCHWARTZ 1996, MERCADER et al. 2002, entre outros).

A presença de artefatos na parte superior das linhas de seixos africanas foi utilizada por muitos autores como argumento a favor da hipótese de paleopavimento. DE PLOEY (1964), LANFRANCHI \& SCHWARTZ (1991) e SCHWARTZ (1996), que estudaram a região do Congo, são favoráveis a essa idéia. No entanto, como observado nos estudos experimentais de CAHEN\&MOEYERSONS(1977), processos pós-sedimentares catalisados pela atividade biogênica poderiam promover a redistribuição vertical de artefatos contemporâneos. A partir de resultados obtidos na região de Mosumu (Guiné equatorial), MERCADER et al. (2002) chegaram à conclusão de que as implicações paleoecológicas e cronológicas acerca da formação das linhas de seixos podem não ser válidas para reconstruir a ecologia humana, bem como estabelecer a idade das assembléias arqueológicas presentes.

A presença generalizada das linhas de seixos em vastas áreas das zonas intertropicais requer uma atenção especial por parte dos profissionais que lidam com obras de engenharia e agricultura.

AB'SÁBER, já em 1962, resgatava a importância das linhas de seixos na manutenção e segurança da paisagem ao observar a aceleração dos processos de erosão laminar e concentrada, resultantes da retirada do seu material de cobertura. No sudeste do Brasil, esse material é, em geral, denso e coeso, menos sujeito a ravinamentos que o regolito subjacente.

Atualmente, nas paisagens de campos de altitude do Planalto de Campos do Jordão e do domínio morfoclimático dos mares-de-morros, no vale do rio Paraíba do Sul, ficam mais que evidentes os danos provocados pela ausência de práticas adequadas de manejo do solo.

\section{CONCLUSÕES}

Apesar das linhas de seixos serem mencionadas na literatura desde o século XIX, sua origem é um tema que ainda desperta polêmica. As diferentes hipóteses para explicar sua origem não são necessariamente excludentes; muitas vezes, se complementam. A complexidade do tema é também evidenciada pelo caráter poligenético de muitas linhas de seixos. Para o melhor entendimento da questão é essencial que as pesquisas possuam um caráter multidisciplinar, com o envolvimento de pedólogos, geólogos, geomorfólogos e biólogos.

Os estudos sobre a origem das linhas de seixos envolvem diferentes níveis de abordagem, desde observações geomorfológicas regionais e locais, experimentos in situ, até análises micromorfológicas e químicas. Novas técnicas e métodos vêm permitindo refinar o entendimento dos processos que atuam na formação dessas feições, com destaque para os estudos desenvolvidos na área de geomorfologia experimental.

A grande dificuldade está em extrapolar os resultados das observações para escalas temporo-espaciais diferentes. Em alguns casos, como no Planalto de Campos do Jordão, a grande extensão e continuidade lateral das linhas de seixos nos topos de interflúvio, assentadas diretamente sobre a rocha alterada pré-cambriana - que apresenta a estrutura totalmente preservada, sem evidências de retrabalhamento pela ação biológica - são importantes argumentos a favor da hipótese de paleopavimento detrítico.

Uma das questões principais que diferenciam as interpretações sobre a origem das linhas de seixos é o papel das mudanças climáticas durante o Quaternário. Conforme DE PLOEY (1964) e AB'SÁBER (1962), entre outros, a formação do pavimento detrítico estaria associada à vigência de climas semi-áridos. No entanto, outros mecanismos de geração de linhas de seixos associados à ação biológica, processos coluvionares e/ou geoquímicos, não estão vinculados a mudanças ambientais.

As implicações práticas do estudo das linhas de seixos são amplas e variadas, fornecendo subsídios 
para as atividades de prospecção mineral e de levantamento geológico, bem como para a preservação da paisagem.

\section{REFERÊNCIAS}

AB'SÁBER, A.N. 1962. Revisão dos conhecimentos sobre o horizonte sub-superficial de cascalhos inhumados do Brasil Oriental. Curitiba, Boletim da Universidade do Paraná, Geografia Física $2: 1-32$.

AB'SÁBER, A.N. 1969a. Uma revisão do quaternário paulista: do presente para o passado. Revista Brasileira de Geografia, Rio de Janeiro, 31(4): $1-52$.

AB'SÁBER, A.N. 1969b. Ocorrências de "stonelines" na região de São Paulo. Geomorfologia, 10, IGEOG/USP, São Paulo, 9-10.

AB'SÁBER, A.N. 1969c. Contribuição ao estudo das "stone-lines" do sul do Brasil. Geomorfologia, 10, IGEOG/USP, São Paulo, 11-12.

AB'SÁBER, A.N. 1971. A organização natural das paisagens inter e subtropicais brasileiras. III Simpósio sobre o Cerrado, Editora Blücher e Editora da Universidade de São Paulo. (Republicado em inglês na Revista do Instituto Geológico 21(1/2), p.57-70, São Paulo, 2000, Natural organization of Brazilian inter and sub-tropical landscapes).

AB'SÁBER, A.N. 1973. A organização das paisagens inter e subtropicais brasileiras. Geomorfologia, 41, IGEOG/USP, São Paulo, 39p.

AB'SÁBER, A.N. 1977. Espaços ocupados pela expansão dos climas secos na América do Sul, por ocasião dos períodos glaciais quaternários. $\mathrm{Pa}$ leoclimas, 3, IGEOG-USP, São Paulo.

AB'SÁBER, A.N. 1979. Limitações dos informes paleoecológicos das linhas de pedras no Brasil. Interfácies, IBILCE/UNESP, 1: 1-27.

AB'SÁBER, A.N. 1980. Razões da retomada parcial de semi-aridês holocênica, por ocasião do optimum climaticum - Primeiras idéias. Inter-Facies, $\mathrm{n}^{\circ}$ 8, IBILCE-UNESP, São José do Rio Preto, 13 p.

AB'SÁBER, A.N. 1996. A Amazônia: do Discurso à Práxis. Editora da Universidade de São Paulo, 319 p.
AB'SÁBER, A.N. 2003. Os domínios de natureza no Brasil - Potencialidades paisagísticas. Ateliê Editorial, São Paulo, 160 p.

ALEVA, G.J.J. 1983. On weathering and denudation of humid tropical interfluves and their triple planation surfaces. In: M.W. Van den Berg \& R. Felix (eds.): Special issue in the honour of J.D. de Jong - Geologie en Mijnbouw, 62: 383-388.

ALEVA, G.J.J. 1987. Occurrence of stone-lines in tin-bearing areas in Belitung, Indonesia, and Rondônia, Brazil. Geo-Eco-Trop, 11(1-4): $197-$ 203.

ALEVA, G.J.J.1991. Tropical weathering, denudation and mineral accumulation. Geologie en Mijnbouw, 70: 35-38.

ALONI, J. 1975. Le sol et l'évolution morphologique des termitières géantes du Haut-Shaba (Rép. Zaîre). Bruxelas, Pédologie, XXV (1): 25-39.

ALONI KOMANDA, J. 1978a. Le rôle des termites dans la mise en place des sols de plateau dans le Shaba meridional. Geo-Eco-Trop, 2(1): 81-93.

ALONI KOMANDA, J. 1978b. Terrains superficiels et érosion des grandes termitières au Shaba (problèmes de méthodologie). São Paulo, Colóquio "Estudo e cartografia de formações superficiais e suas aplicações em regiões tropicais", vol. 1, 189-200.

BIGARELLA, J.J. \& ANDRADE, G.O. 1965. Contribution to the study of the Brazilian Quaternary. In: International Studies on the Quaternary, Geol. Soc. of America, Special Paper, 84: 433-451.

BIGARELLA, J.J. \& MOUSINHO, M.R. 1965. Significado paleogeográfico e paleoclimático dos depósitos rudáceos. Boletim Paranaense de Geografia, Universidade do Paraná - Curitiba, 16/17: 7-16.

BOURGEAT, F. \& PETIT, M. 1966. Les "stonelines"et les terrasses alluviales des hautes terres malgaches. Cahiers Orstom, sér. Pédologie, 4(2): 3-19.

BOYER, P. 1959. De l'influence des termites de la zone intertropicale sur la configuration de certains sols. Revue de Géomorphologie Dynamique, Ano X (1-2, 3-4): 41-44. 
BRAUCHER, R.; COLIN, F.; BROWN, E.T.; BOURLĖS, D.L.; BAMBA, O.; RAISBECK, G.M.; YIOU, F.; KOUD, J.M. 1998a. African laterite dynamics using in situ-produced ${ }^{10} \mathrm{Be}$. Geochimica et Cosmochimica Acta, 62(9): 1501-1507.

BRAUCHER, R.; BOURLÈS, D.L.; COLIN, F.; BROWN, E.T.; BOULANGÉ, B. $1998 \mathrm{~b}$. Brazilian laterite dynamics using in situproduced ${ }^{10} \mathrm{Be}$. Earth and Planetary Science Letters, 163: 197-205.

BRAUCHER, R.; LIMA, C.V.; BOURLÈS, D.L.; GASPAR, J.C.; ASSAD, M.L.L. 2004. Stoneline formation processes documented by in situ-produced ${ }^{10} \mathrm{Be}$ distribution, Jardim River basin, DF, Brazil. Earth and Planetary Science Letters, 222: 645-651.

BROWN, D.J.; MCSWEENEY, K.; HELMKE, P.A. 2004. Statistical, geochemical, and morphological analyses of stone line formation in Uganda. Geomorphology, 62: 217-237.

BÜDEL, J. 1957. Die “doppelten Einebnungsflächen” in den feuchten Tropen. Zeitschrift für Geomorphologie, N.F., Band 1: 201-228.

CAHEN, D. \& MOEYERSONS, J. 1977. Subsurface movements of stone artifacts and their implications for the prehistory of Central Africa. Nature, 266: 12-815.

CAILLEUX, A. 1957. La ligne de cailloutis à la base des sols jaunes. Zeitschrift für Geomorphologie, Band I: 312 (traduzido Not. Geomorf., 4, 1959, Campinas).

CAILLEUX, A. \& TRICART, J. 1957. Zones phytogéographiques et morphoclimatiques au Quaternaire, au Brésil. C.R. Soc. Biogeographique, a93, p. 7-13, Paris (Tradução em Notícia Geomorfológica n ${ }^{\circ}$ 4, ano II, p.1217, 1959).

COCKBURN, H.A.P. \& SUMMERFIELD, M.A. 2004. Geomorphological applications of cosmogenic isotope analysis. Progress in Physical Geography, 28(1): 1-42.

COLLINET, J. 1969. Contribution a l'étude des "stone-lines" dans la region du Moyen-Ogooué (Gabon). Cahiers Orstom, sér. Pédologie, 7(1): 3-42.
DE DAPPER, M. 1987. Pedisediments and stoneline complexes in Peninsular Malaysia. GeoEco-Trop, 11(1-4): 37-59.

DE HEINZELIN, J. 1952. Sols, paléosols, et désertifications anciennes dans le secteur nord-oriental du bassin du Congo. Publication INEAC, 172p.

DE HEINZELIN, J., 1955. Observations sur la genèse des nappes de gravats dans les sols tropicaux. Publication INEAC, Série Scientifique, vol. 64, $37 \mathrm{p}$.

DE PLOEY, J. 1964. Nappes de gravats et couvertures argilo-sableuses au Bas-Congo: leur genèse et l'action de térmites. In: "Études sur les termites africains", ed. de l'Université, Léopoldville, 400-414.

DE PLOEY, J. 1985. O estudo dos processos geomorfológicos e a interpretação dos depósitos quaternários. Revista do Instituto Geológico, 6(1/2): $7-13$.

DE PLOEY, J. \& POESEN, J. 1987. Experimental geomorphology and the interpretation of stonelines. Geo-Eco-Trop, 11(1-4): 75-82.

EMBRECHTS, J. \& DE DAPPER, M. 1987. Hillslope pedimentation and stone-layers in the hilly áreas of Southern Cameroon. Geo-EcoTrop, 11(1-4): 61-74.

EMBRECHTS, J. \& DE DAPPER, M. 1990. Morphologie, gênese et sédimentologie des pédiments de versant de la région du MontFébe (Cameroun meridional). In: Paysages quaternaires de l'Afrique centrale atlantique (eds.: LANFRANCHI, R. \& SCHWARTZ, D.), p. 138-154.

FAIRBRIDGE, R.W. \& FINKL, C.W. 1984. Tropical stone lines and podzolized sand plains as paleoclimatic indicators for weathered cratons. Quaternary Science Reviews, 3: 41-72.

GRASSÉ, P. \& NOIROT, C. 1959. Rapports des termites avec les sols tropicaux. Revue de Géomorphologie Dynamique, Ano X (1-2, 3-4): 35-40.

JOHNSON, D.L. 1989. Subsurface stone lines, stone zones, artifact-manuport layers, and biomantles produced by bioturbation via pocket gophers 
(Thomomys Bottae). American Antiquity, 54(2): 370-389.

LANFRANCHI, R. \& SCHWARTZ, D. 1991. Les remaniements de sols pendant le Quaternaire supérieur au Congo. Évolution des paysages dans la region de la Sangha. Cahiers Orstom, sér. Pédologie, 26(1): 11-24.

LAPORTE, G. 1962. Reconnaissance pédologique le long de la voie ferrée Comilog (CongoBrazzaville). IRSC MC 119, Brazzaville, $149 \mathrm{p}$.

LECOMTE, P. 1988. Stone line profiles: importance in geochemical exploration. Journal of Geochemical Exploration, 30: 35-61.

LEHMANN, H. 1957. Klimamorphologische Beobachtungen in der Serra da Mantiqueira und in Paraiba Tal (Brasilien). - Abhandlungen des Geographischen Instituts der Frein Universitaet Berlin, (Sep. do tomo 5 do "Geomorphologische Abhandlungen”, p. 67-72). (Tradução em Notícia Geomorfológica, 5, abril de 1960, Campinas).

LUCAS, Y.; BOULET, R.; CHAUVEL, A. 1990. Modalités de la formation in situ de stone lines en zone équatoriale. Exemple d'une couverture ferrallitique d'Amazonie au Brésil. C.R. Acad. Sci. Paris, t. 311, Série II, p. 713-718.

MBENZA, M.; ALONI, K.; LUBUIMI, M.L. 1987. Le role des rats-taupes dans la mise em place actuelle de certains pavages résiduels des sols des régions tropicales humides à saisons contrastées. Geo-Eco-Trop, 11(1-4): 127-137.

MCFARLANE, M.J. \& POLLARD, S. 1987. Some aspects of stone-lines and dissolution fronts associated with regolith and dambo profiles in parts of Malawi and Zimbabwe. Geo-Eco-Trop, 11(1-4): 23-35.

MERCADER, J.; MARTÍ, R.; MARTÍNEZ, J.L.; BROOKS, AL. 2002. The nature of "stonelines" in the African Quaternary record: archaeological resolution at the rainforest site of Mosumu, Equatorial Guinea. Quaternary International, 89: 71-96.

MIKLOS, A.A.W. 1992. Biodynamics of the landscape: biopedological organization and functioning. Part 1: role and contribution of the soil fauna to the organization and dynamics of a pedological cover in Botucatu, state of São Paulo, Brazil. In: International Scientific Conference IFOAM "Organic agriculture, a key to a sound development and a sustainable environment", 9, São Paulo, Proceedings, 74-86.

MIKLOS, A.A.W. 1993. Biodinâmica da paisagem: organização e funcionamento biopedológico. Boletim do Instituto Biodinâmico de Desenvolvimento Rural, 11(69): 9-16.

MODENESI, M.C. 1988. Significado dos depósitos correlativos quaternários em Campos do Jordão - São Paulo: implicações paleoclimáticas e paleoecológicas. São Paulo, Instituto Geológico, 155 p. (Boletim 7)

MOEYERSONS, J. 1987. The concentration of stones into a stone-line, as a result from subsurface movements in fine and loose soils in the tropics. Geo-Eco-Trop, 11(1-4): 11-22.

MOUSINHO, M.R. \& BIGARELLA, J.J. 1965. Movimentos de massa no transporte dos detritos da meteorização das rochas. Boletim Paranaense de Geografia, Universidade do Paraná - Curitiba, 16/17: 43-84.

NICOLA, S.M.C. 1993. Sistemas pedológicos desenvolvidos sobre basalto, na região de Ilha Solteira (Estado de São Paulo - Brasil): gênese e transformações. Tese de Doutorado, Instituto de Geociências, Universidade de São Paulo, vol. I texto (116p.) e vol. II (Anexos).

OZER, A. 1987. Signification des "lignes de galets" observées dans les dépôts quaternaires de la Sardaigne septentrionale. Geo-Eco-Trop, 11(14): $83-92$.

PARIZEK, E.J. \& WOODRUFF, J.F. 1957. Description and origin of stone layers in soils of the Southern States. Journal of Geology, 65(1): 24-34.

PENTEADO, M.M. 1969. Novas informações a respeito dos pavimentos detríticos (stone-lines). Notícia Geomorfológica, 9(17): 15 - 41 .

PORTO, C.G. \& HALE, M. 1995. Gold redistribution in the stone line lateritic profile of the Posse Deposit, central Brazil. Economic Geology, 90(2): 308-321. 
QUEIROZ NETO, J.P. 2001. O estudo de formações superficiais no Brasil. Revista do Instituto Geológico, 22(1/2): 65-78.

RAYNAL, R. 1957. Les formations des versants et l'évolution climatique dans la Serra da Mantiqueira. Zeitschrift für Geomorphologie, Band I: 279-289.

RIQUIER, J. 1969. Contribution a l' étude des "stone lines" en régions tropicale et équatoriale. Cah. Orstom, sér. Pédologie, 7(1) : 71-110.

RODRIGUEZ, S.K. 1994. Comentários a respeito de depósitos stone lines. In: SBG, CONGRESSO BRASILEIRODE GEOLOGIA, 38, Camboriú, Resumos Expandidos, 3: 189-190.

RUHE, R.V. 1956. Landscape evolution in the HighIturi, Belgian Congo. Publication INEAC, Série Scientifique, vol. 66.

RUHE, R.V. 1959. Stonelines in soils. Soil Science, 87: 223-231.

SCHWARTZ, D. 1996. Archeologie prehistorique et processus de formation des stone-lines em Afrique Centrale (Congo-Brazzaville et zones peripheriques). Geo-Eco-Trop, 20(1/4): 15-38.

SEGALEN, P. 1969. Le remaniement des sols et la mise en place de la stone-line en Afrique. Cah. Orstom, sér. Pédologie, 7(1) : 113-131.

SOYER, J. 1987. Rôle des termites dans la formation du complexe de la stone-line. Geo-Eco-Trop, 11(1/4): 97-108.

THOMAS, M.F. 1989a. The role of etch processes in landform development. I. Etching concepts and their applications. Zeitschrift für Geomorphologie, N.F. 33: 129-142.

THOMAS, M.F. 1989b. The role of etch processes in landform development. II. Etching and the formation of relief. Zeitschrift für Geomorphologie, N.F. 33: 257-274.
THOMAS, M.F. 1994. Geomorphology in the tropics. John Wiley \& Sons, Chichester, $460 \mathrm{p}$.

THOMAS,M.F.\&THORP,M.B. 1985.Environmental change and episodic etchplanation in the humid tropics of Sierra Leone: the Koidu etchplain. In: Environmental Change and Tropical Geomorphology (I. Douglas \& T. Spencer, eds.), London, George Allen \& Unwin, 239267.

THORP, M.B. 1987. The economic significance of stone-lines. Geo-Eco-Trop, 11(1/4): 225-227.

TRICART, J. 1958. Division morphoclimatique du Brésil atlantique centrale. Revue de Geom. Dynam., IX, nº 1 e 2, jan.-fev. 1958. (Transcrição no Boletim Paulista de Geografia, $\mathrm{n}^{\circ} 31$, março de 1959, p. 3-44, São Paulo).

VOGT, J. 1966. A - Le complexe de la stone-line. Mise au point. In: Terrains d'alteration et de recouvrement en zone intertropical (Vogt, J. \& Vincent, P.L.). Bulletin du Bureau de Recherches Géologiques et Minières, $\mathrm{n}^{\circ}$ 4, p. 3-49.

WAYLAND, E.J. 1933. Peneplains and some other erosional platforms. Annual Report and Bulletin, Protectorate of Uganda Geological Survey, Department of Mines, Note 1, 77-79.

WELLS, N.A.; ANDRIAMIHAJA, B.; RAKOTOVOLOLONA, H.F.S. 1990. Stonelines and landscape development on the laterized craton of Madagascar. Geological Society of America Bulletin, 102(5): 615-627.

WELLS, S.G.; MCFADDEN, L.D.; POTHS, J.; OLINGER, C.T. 1995. Cosmogenic ${ }^{3} \mathrm{He}$ surface-exposure dating of stone pavements: implications for landscape evolution in deserts. Geology, 23(7): 613-616.

WILLIS, B. 1936. East African plateaus and rift valleys - Studies in comparative seismology. Carnegie Institute, Washington, Publication, 470.

Endereço do autor:

Silvio Takashi Hiruma - Seção de Geomorfologia, Instituto Geológico, Secretaria do Meio Ambiente do Estado de São Paulo, Avenida Miguel Stéfano, 3900, CEP 04301-903, Água Funda, São Paulo, SP.

E-mail: hiruma@igeologico.sp.gov.br 